\title{
Distribuição de gorduras internas e de descarte e componentes externos do corpo de novilhos de gerações avançadas do cruzamento rotativo entre as raças Charolês e Nelore
}

\author{
Luís Fernando Glasenapp de Menezes ${ }^{1}$, João Restle ${ }^{2}$, Ivan Luiz Brondani ${ }^{2}$, Dari Celestino \\ Alves Filho ${ }^{3}$, Leonir Luiz Pascoal ${ }^{3}$, José Henrique Souza da Silva ${ }^{3}$
}

\author{
1 Universidade Tecnológica Federal do Paraná (UTFPR), Campus Dois Vizinhos. \\ 2 PPGZ da UFSM. Bolsista Produtividade CNPq. \\ ${ }^{3}$ Departamento de Zootecnia - UFSM.
}

RESUMO - Foram avaliados os efeitos de heterose e grupo genético na distribuição das gorduras internas e de descarte e dos componentes externos do corpo de novilhos puros, Charolês (C) e Nelore $(\mathrm{N})$, e mestiços de segunda $(3 / 4 \mathrm{C} \times 1 / 4 \mathrm{~N}$ e $3 / 4 \mathrm{~N} \times 1 / 4 \mathrm{C})$, terceira $(5 / 8 \mathrm{C} \times 3 / 8 \mathrm{~N}$ e $5 / 8 \mathrm{~N} \times 3 / 8 \mathrm{C})$ e quarta gerações $(11 / 16 \mathrm{C} \times 5 / 16 \mathrm{~N}$ e $11 / 16 \mathrm{~N} \times 5 / 16 \mathrm{C})$ de cruzamento terminados em confinamento. Em comparação à média dos puros, os novilhos de segunda geração apresentaram maior peso absoluto das gorduras renal, intestinal e total, resultando em heterose de 39,88; 43,96 e 31,80\%, respectivamente. A gordura ruminal dos novilhos da quarta geração foi 41,48\% maior que a média dos puros. Quando expressa em porcentagem do peso do corpo vazio (PCV), os animais da segunda geração foram superiores aos puros somente em relação à gordura intestinal, apresentando heterose de $28,06 \%$. Os animais de quarta geração foram $21,67 \%$ inferiores aos puros quando a gordura de toalete foi expressa por $100 \mathrm{~kg}$ de PCV. Novilhos Charolês tiveram maior peso absoluto de gordura de descarte em relação aos novilhos Nelore (2,85 vs $1,30 \mathrm{~kg})$. Nos novilhos $3 / 4 \mathrm{C} \times 1 / 4 \mathrm{~N}$, a gordura intestinal foi maior que nos $3 / 4 \mathrm{~N} \times 1 / 4 \mathrm{C}$, em pesos absoluto $(10,15$ vs $7,83 \mathrm{~kg}$ ) e relativo (2,59 vs 2,02\%). O peso de gordura ruminal nos animais $11 / 16 \mathrm{~N} \times 5 / 16 \mathrm{C}$ foi maior que nos $11 / 16 \mathrm{C} \times 5 / 16 \mathrm{~N}$ (6,93 vs 4,94 kg). A heterose para o peso relativo da cabeça foi significativa na terceira $(-15,54 \%)$ e quarta $(-13,12 \%)$ gerações de cruzamento, enquanto a heterose para o peso relativo das patas foi significativa apenas na terceira geração $(-11,08 \%)$. O peso relativo das patas nos novilhos Charolês foi maior que nos Nelore (2,18 vs 1,88\%). As gorduras não-integrantes da carcaça apresentam heterose significativa no cruzamento rotativo entre as raças Charolês e Nelore.

Palavras chave: Bos indicus, Bos taurus, gordura interna, gordura renal, heterose, peso de corpo vazio

\section{Distribution of internal and trim fat and external components of the body of steers from advanced generations of rotational Charolais $\times$ Nellore crossbreeding}

\begin{abstract}
The effect of heterosis and genetic group on the distribution of internal and trim fat and, external components of the body of purebred, Charolais (C) and Nellore (N), and crossbred steers from second (G2) $(3 / 4 \mathrm{C} 1 / 4 \mathrm{~N}$ and $3 / 4 \mathrm{~N} \mathrm{1/4C)}$, third (G3) (5/8C 3/8N and 5/8N 3/8C) and fourth (G4) (11/16C 5/16N and 11/16N 5/16C) generations of feedlot finished rotational crossbreeding were evaluated. Steers from G2 showed higher absolute weight for renal, intestinal and total fat when compared to purebreds' average, resulting in heterosis of 39.88, 43.96 and 31.80\%, respectively. Ruminal fat of G4 steers was $41.48 \%$ higher than purebreds' average. When expressed as percentage of empty body weight (EBW), G2 remained superior to purebreds only for intestinal fat, with heterosis $28.06 \%$. Trim fat expressed per $100 \mathrm{~kg}$ of EBW in G4 was $21.67 \%$ lower than purebreds' average. Charolais steers had higher absolute trim fat weight when compared to Nellore ( $2.85 \mathrm{vs} 1.30 \mathrm{~kg})$. The $3 / 4 \mathrm{C} 1 / 4 \mathrm{~N}$ steers had higher intestinal fat than $3 / 4 \mathrm{~N} 1 / 4 \mathrm{C}$ steers, in absolute $(10.15 \mathrm{vs} 7.83 \mathrm{~kg})$ and relative weight (2.59 vs $2.02 \%$ ). The $11 / 16 \mathrm{~N} 5 / 16 \mathrm{C}$ steers showed higher ruminal fat weight when compared to $11 / 16 \mathrm{C}$ 5/16N steers (6.93 vs $4.94 \mathrm{~kg}$ ). Heterosis for relative head weight was negative and significant in G3 (-15.54\%) and G4 (-13.12\%), whereas the relative feet weight was only significant in G3 (-11.08\%). Relative feet weight of Charolais steers was higher than for Nellore (2.18 vs $1.88 \%)$. The carcass non-integrant fats show significant heterosis in the rotational Charolais $\times$ Nellore crossbreeding.
\end{abstract}

Key Words: Bos indicus, Bos taurus, empty body weight, heterosis, internal fat, renal fat 


\section{Introdução}

A gordura no corpo de bovinos distribui-se na forma de depósitos subcutâneos, inter e intramusculares e de gorduras visceral e cavitária. Segundo Perón et al. (1993), o tamanho relativo de cada depósito de gordura é influenciado pela raça e pelo estado fisiológico e nutricional do animal. Pacheco et al. (2005) traçaram equações de regressão para determinar o grau de deposição das características relacionadas a gordura em relação à primeira gordura a ser acumulada na carcaça, a intermuscular. Di Marco (1998) afirmou que a deposição de gordura no corpo do animal ocorre de acordo com a seguinte escala decrescente: intermuscular, subcutânea, interna, visceral e intramuscular.

A distribuição relativa da gordura entre os depósitos corporais pode afetar as exigências energéticas dos bovinos. Thompson et al. (1983) relataram que a atividade metabólica do tecido adiposo interno parece ser maior que a do tecido adiposo periférico, acarretando, com isso, diferenças no requerimento de energia para mantença. Segundo o NRC (1996), a utilização do teor de gordura interna é de suma importância para determinação das exigências dos animais. Solis et al. (1988) observaram menor exigência de mantença para vacas Brahman em comparação a raças taurinas e atribuíram esse resultado, à menor deposição de gordura interna e à menor atividade metabólica dos órgãos internos desses animais.

De acordo com Leme et al. (2000), as gorduras renal, pélvica e inguinal, expressas em peso absoluto ou relativo, são o melhor indicador da deposição de gordura corporal. Segundo esses autores, a espessura de gordura da carcaça é muitas vezes prejudicada no momento da retirada do couro. Além disso, o excesso de gordura é retirado antes da pesagem da carcaça e, portanto, não é incluído na remuneração ao produtor.

As características relacionadas à deposição de gordura são as que apresentam maior heterose (Slanger et al., 1985; Urick et al., 1989; Restle et al., 2002; Vaz et al., 2002). No entanto, a porcentagem de heterose para deposição de gordura depende das raças envolvidas no cruzamento. Hedrick et al. (1975) observaram heterose de 19,8\% para o depósito de gordura visceral ao utilizarem no cruzamento uma raça continental (Charolês) e uma britânica (Aberdeen Angus). Quando o cruzamento envolveu as raças britânicas Aberdeen Angus e Hereford, a heterose foi de 0\%. Baixos valores de heterose para essas características no cruzamento entre raças britânicas são reportados por vários autores (Long \& Gregory, 1975; Gregory et al., 1978; Marshal et al., 1987). Kuss et al. (2007), estudando a terminação de vacas de descarte, não observaram interferência do grupo genético, da predominância racial ou da geração de cruzamento sobre a quantidade de gordura interna, de descarte e total.

Além de aspectos nutricionais, o estudo das partes não-integrantes da carcaça tem importância econômica, tanto para o produtor como para a indústria, uma vez que com o aumento da deposição de gordura, ocorre redução na eficiência alimentar, e a lucratividade dos frigoríficos passa pela comercialização de todas as partes do animal, desde a carcaça até as partes não integrantes. Entre os componentes externos da carcaça, o couro é o mais valorizado considerando o valor agregado do abate até a industrialização. $\mathrm{O}$ peso do couro é influenciado pelo peso dos animais (Restle et al., 2005) e pelo grupo genético (Galvão et al., 1991). Animais zebuínos tendem a apresentar couro mais pesado que o de animais europeus (Peron et al., 1993), em decorrência da presença da barbela e da giba. Galvão et al. (1991) verificaram maior peso relativo do couro dos animais Nelore em relação aos seus mestiços com Limousin e Marchigiana. Também Pacheco et al. (2005) observaram maior peso absoluto de couro para animais com predominância zebuína $(5 / 8 \mathrm{~N} 3 / 8 \mathrm{C})$ em relação àqueles com predominância européia (5/8C 3/8N).

Portanto, o experimento foi realizado com o objetivo de avaliar a distribuição de gorduras internas e de descarte e os componentes externos do corpo de novilhos de gerações avançadas do cruzamento rotativo entre as raças Charolês e Nelore terminados em confinamento.

\section{Material e Métodos}

O trabalho foi realizado no Setor de bovinocultura de corte do Departamento de Zootecnia da Universidade Federal de Santa Maria (UFSM).

Comparou-se o efeito da composição racial e a heterose nas características quantitativas da carcaça de novilhos puros (Charolês - C e Nelore - N) e mestiços de segunda (G2) (3/4 C $\left.1 / 4 \mathrm{~N} \mathrm{e}^{3 / 4} \mathrm{~N} 1 / 4 \mathrm{C}\right)$, terceira (G3) (5/8C 3/8N e 5/8N 3/8C) e quarta (G4) (11/16C 5/16N e 11/16N 5/16C) gerações de cruzamento. A heterose apresentada neste trabalho é a total, decorrente da heterozigose individual e materna.

Foram utilizados 57 novilhos tomados ao acaso da fazenda experimental da UFSM, nascidos na mesma época de parição e mantidos sempre sob as mesmas condições de manejo e alimentação. Os novilhos foram gerados por fêmeas puras e mestiças inseminadas com sêmen de seis touros de cada raça, Charolês e Nelore. Quatro touros de cada raça foram utilizados para o repasse na monta a campo. Os touros Charolês que geraram os novilhos Charolês foram os 
mesmos que geraram os novilhos $3 / 4 \mathrm{C} 1 / 4 \mathrm{~N}, 5 / 8 \mathrm{C} 3 / 8 \mathrm{Ne}$ $11 / 16 \mathrm{C} 5 / 16 \mathrm{~N}$, assim como os touros Nelore que geraram os novilhos Nelore foram os mesmos que geraram os novilhos $3 / 4 N^{1} 1 / 4$ C, 5/8N 3/8C e 11/16N 5/16C.

Ao início do período de terminação em confinamento, os animais apresentavam em média 20 meses de idade e $304 \mathrm{~kg}$ de peso vivo. O período total de confinamento foi de 97 dias; nos primeiros 14 dias, os animais foram submetidos à adaptação ao ambiente do confinamento e à dieta alimentar. A dieta foi calculada para proporcionar aos animais ganho de peso médio diário de 1,2 kg (NRC, 1996) e foi igual para todos os animais, com $12,32 \%$ de proteína bruta (PB), 2,96 Mcal de energia digestível e 58,30\% de fibra em detergente neutro (FDN). O volumoso, representando $52 \%$ da matéria seca total oferecida, foi constituído de silagem de milho (AG 5011). O concentrado foi composto de 93,97\% de farelo de trigo, 1,5\% de uréia, 3,62\% de calcário calcítico e $0,9 \%$ de sal. Foi ainda adicionada monensina sódica, conforme recomendação do fabricante.

Após 97 dias de confinamento, os animais foram pesados, após jejum de sólidos de 14 horas, e embarcados para um frigorífico comercial, onde foram abatidos na chegada. $\mathrm{O}$ abate seguiu o fluxo normal do estabelecimento. No momento do abate, foram tomados os pesos da cabeça, chifres, patas, sangue, couro, vassoura da cauda, retículorúmen, omaso, abomaso, intestino delgado, intestino grosso, coração, rins, fígado, pulmões e as gorduras internas (inguinal, renal, ruminal e de toalete). O peso de carcaça mais o somatório de todos estes componentes resultou no peso de corpo vazio, que representa o peso do animal sem o conteúdo do trato gastrintestinal.

Odelineamento experimental utilizado foi o inteiramente casualizado, com número diferente de repetições por grupo genético.

Os resultados dos pesos absolutos e relativos das gorduras internas e dos componentes externos foram analisados por análise de variância e as médias comparadas pelo teste $\mathrm{t}(\mathrm{SAS}, 1997)$ utilizando-se o seguinte modelo estatístico:

$$
\mathrm{Y}_{\mathrm{ijk}}=\mu+\mathrm{IV}_{\mathrm{k}}+\mathrm{SA}_{\mathrm{i}}+\mathrm{GG}_{\mathrm{j}}\left(\mathrm{SA}_{\mathrm{i}}\right)+\mathrm{E}_{\mathrm{ijk}}
$$

em que $Y_{i j k l}=$ a variáveis dependentes; $\mu=$ média de todas as observações; $\mathrm{IV}_{\mathrm{k}}=$ efeito da k-ésima idade da vaca, mãe do novilho; $\mathrm{SA}_{\mathrm{i}}=$ efeito do sistema de acasalamento de índice $\mathrm{i}$, em que $\mathrm{i}=1$ (puros), 2 (cruzados da G2), 3 (cruzados da G3) e 4 (cruzados da quarta geração); $\mathrm{GG}_{\mathrm{j}}\left(\mathrm{SA}_{\mathrm{i}}\right)=$ efeito do grupo genético de índice $\mathrm{j}$ aninhados dentro do sistema de acasalamento $\mathrm{i}$, em que j $=1$ (Charolês) e 2 (Nelore) dentro do sistema de acasalamento $1 ; 1\left(3 / 4 \mathrm{C}^{1 / 4} \mathrm{~N}\right)$, e $2\left(3 / 4 \mathrm{~N}^{1 / 4} \mathrm{C}\right)$ dentro do sistema de acasalamento 2; 1 (5/8 C 3/8 N) e 2
(5/8 N 3/8 C) dentro do sistema de acasalamento 3; 1 (11/16C 5/16N) e 2 (11/16 N 5/16 C) dentro do sistema de acasalamento $4 ; \mathrm{E}_{\mathrm{ijkl}}=$ efeito aleatório residual.

Foram realizadas análises de contraste entre mestiços e Charolês ou Nelore para as variáveis estudadas (pesos absolutos e relativos das gorduras internas e componentes externos do corpo dos animais).

A heterose resultante para as características avaliadas nas diferentes gerações de cruzamento foi estimada por:

H\%=[(média dos cruzados dentro de cada geração/ médias dos puros)-1] x 100.

A heterose retida foi estimada segundo a equação: Hretida $=[$ (média de todos os cruzados/média dos puros)-1] x 100.

\section{Resultados e Discussão}

Os animais da segunda geração de cruzamento apresentaram maior deposição de gordura nos diferentes locais em relação à média dos puros, com heterose significativa para a quantidade de gordura renal, intestinal e total (Tabelas 1, 2 e 3) . Não houve efeito da heterozigose sobre a deposição de gordura nos animais da terceira geração, enquanto na quarta geração houve heterose significativa apenas para gordura ruminal. A heterose retida foi positiva para a quantidade de gordura nos diferentes locais e foi significativa para gorduras intestinal (31,65\%) e total $(19,34 \%)$. As características relacionadas à deposição de gordura são as que apresentam maior heterose (Slanger et al., 1985; Urick et al., 1989; Vaz et al. 2002). No entanto, a porcentagem de heterose para deposição de gordura depende das raças envolvidas no cruzamento. Hedrick et al. (1975) observaram heterose para a deposição de gordura visceral de 19,8\% ao utilizarem no cruzamento uma raça continental (Charolês) e uma britânica (Aberdeen Angus). Quando o cruzamento envolveu as raças britânicas Aberdeen Angus e Hereford, a heterose foi de $0 \%$. Baixos valores para heterose para estas características no cruzamento entre raças britânicas foram reportados por vários autores (Long \& Gregory, 1975 (0,9\%); Gregory et al., 1978 (0,0\%); Marshal et al., $1987(0,4 \%))$. Neste estudo, a elevada heterose retida para a quantidade absoluta de gordura intestinal e total deve-se às raças envolvidas, uma européia e uma zebuína. Segundo Koger (1980), quanto maior o distanciamento genético entre as raças, maior o valor esperado para heterose.

Quando os pesos das gorduras foram ajustados para 100 kg de PCV (Tabela 2), a heterose continuou positiva para a gordura depositada nos diferentes locais na segunda geração, no entanto, foi significativa apenas para a gordura 
Tabela 1 - Pesos absolutos das gorduras inguinal, renal, de toalete, do rúmen, do intestino e total de novilhos resultantes de cruzamentos Charolês $\times$ Nelore

\begin{tabular}{|c|c|c|c|c|c|c|}
\hline \multirow[t]{2}{*}{ Grupo genético } & \multicolumn{5}{|c|}{ Gordura (kg) } & \multirow[b]{2}{*}{ Total } \\
\hline & Inguinal & Renal & Toalete & Ruminal & Intestinal & \\
\hline Charolês (C) & $2,55 \pm 0,4$ & $6,16 \pm 1,2$ & $2,85 \pm 0,6 a$ & $5,01 \pm 1,2$ & $7,23 \pm 1,1$ & $26,11 \pm 3,3$ \\
\hline Nelore (N) & $2,17 \pm 0,3$ & $3,92 \pm 1,1$ & $1,30 \pm 0,5 b$ & $3,38 \pm 1,1$ & $5,26 \pm 0,9$ & $18,48 \pm 2,9$ \\
\hline Média puros & $2,36 \pm 0,2$ & $5,04 \pm 0,8$ & $2,07 \pm 0,4$ & $4,20 \pm 0,8$ & $6,25 \pm 0,7$ & $22,29 \pm 2,1$ \\
\hline $3 / 4 \mathrm{C} 1 / 4 \mathrm{~N}$ & $2,98 \pm 0,3$ & $7,04 \pm 1,1$ & $2,57 \pm 0,5$ & $6,36 \pm 1,1$ & $10,15 \pm 0,9 a$ & $32,25 \pm 2,9$ \\
\hline $3 / 4 \mathrm{~N} 1 / 4 \mathrm{C}$ & $2,55 \pm 0,3$ & $7,06 \pm 0,9$ & $2,63 \pm 0,4$ & $4,26 \pm 0,9$ & $7,83 \pm 0,8 b$ & $26,52 \pm 2,4$ \\
\hline Média G2 & $2,76 \pm 0,2$ & $7,05 \pm 0,7$ & $2,60 \pm 0,3$ & $5,31 \pm 0,7$ & $8,99 \pm 0,6$ & $29,39 \pm 1,9$ \\
\hline Heterose G2, \% & 17,16 & $39,88 *$ & 25,30 & 26,58 & $43,96 * * *$ & $31,80 * *$ \\
\hline $5 / 8 \mathrm{C} 3 / 8 \mathrm{~N}$ & $2,58 \pm 0,2$ & $4,45 \pm 0,6$ & $2,14 \pm 0,3$ & $4,66 \pm 0,6$ & $8,06 \pm 0,8$ & $24,69 \pm 1,8$ \\
\hline $5 / 8 \mathrm{~N} \quad 3 / 8 \mathrm{C}$ & $2,62 \pm 0,2$ & $5,22 \pm 0,5$ & $1,76 \pm 0,3$ & $4,20 \pm 0,5$ & $7,35 \pm 0,7$ & $23,69 \pm 1,6$ \\
\hline Média G3 & $2,60 \pm 0,2$ & $4,83 \pm 0,4$ & $1,95 \pm 0,2$ & $4,43 \pm 0,4$ & $7,70 \pm 0,5$ & $24,19 \pm 1,2$ \\
\hline Heterose G3, \% & 10,17 & $-4,07$ & $-6,02$ & 5,60 & 23,38 & 8,50 \\
\hline $11 / 16 \mathrm{C} \mathrm{5/16} \mathrm{N}$ & $2,80 \pm 0,3$ & $5,01 \pm 0,5$ & $1,72 \pm 0,3$ & $4,94 \pm 0,7 b$ & $8,26 \pm 1,0$ & $25,20 \pm 1,9$ \\
\hline $11 / 16 \mathrm{~N} \mathrm{5/16} \mathrm{C}$ & $2,64 \pm 0,3$ & $5,08 \pm 0,6$ & $2,12 \pm 0,3$ & $6,93 \pm 0,8 a$ & $7,68 \pm 1,2$ & $27,29 \pm 2,1$ \\
\hline Média G4 & $2,72 \pm 0,2$ & $5,05 \pm 0,4$ & $1,92 \pm 0,2$ & $5,94 \pm 0,6$ & $7,97 \pm 0,8$ & $26,24 \pm 1,5$ \\
\hline Heterose G4, \% & 15,25 & 0,10 & $-7,47$ & $41,48 *$ & 27,62 & 17,72 \\
\hline Heterose retida, \% & 14,19 & 11,97 & 3,94 & 24,55 & $31,65 * *$ & $19,34 * *$ \\
\hline Diferença cruzados e C, \% & 5,69 & $-8,39$ & $-24,33 *$ & 4,29 & 13,72 & $1,90 *$ \\
\hline Diferença cruzados e N, \% & 24,19 & $43,96 *$ & 65,90 & $54,59 * *$ & $56,31 * *$ & $43,98 * * *$ \\
\hline
\end{tabular}

$* * * \mathrm{P}<0,01 ; * * \mathrm{P}<0,05 ; * \mathrm{P}<0,10$.

Médias na coluna seguidas por letras diferentes na comparação entre $\mathrm{C}$ e N, ou entre os genótipos dentro da mesma geração de cruzamento, são diferentes ( $<<0,10$ ) pelo teste t.

Tabela 2 - Pesos, em relação a 100 kg de corpo vazio, das gorduras inguinal, renal, de toalete, do rúmen, do intestino e total de novilhos resultantes de cruzamentos Charolês $\times$ Nelore

\begin{tabular}{|c|c|c|c|c|c|c|}
\hline \multirow[t]{2}{*}{ Grupo genético } & \multicolumn{5}{|c|}{ Gordura (\%) } & \multirow[b]{2}{*}{ Total } \\
\hline & Inguinal & Renal & Toalete & Ruminal & Intestinal & \\
\hline Charolês (C) & $0,70 \pm 0,1$ & $1,75 \pm 0,3$ & $0,77 \pm 0,2$ & $1,41 \pm 0,3$ & $1,96 \pm 0,3$ & $7,22 \pm 0,8$ \\
\hline Nelore (N) & $0,69 \pm 0,1$ & $1,22 \pm 0,3$ & $0,43 \pm 0,1$ & $1,04 \pm 0,3$ & $1,64 \pm 0,2$ & $5,78 \pm 0,7$ \\
\hline Média puros & $0,69 \pm 0,1$ & $1,48 \pm 0,2$ & $0,60 \pm 0,1$ & $1,22 \pm 0,2$ & $1,80 \pm 0,2$ & $6,50 \pm 0,5$ \\
\hline $3 / 4 \mathrm{C} 1 / 4 \mathrm{~N}$ & $0,76 \pm 0,1$ & $1,78 \pm 0,3$ & $0,64 \pm 0,1$ & $1,61 \pm 0,3$ & $2,59 \pm 0,2 a$ & $8,19 \pm 0,7$ \\
\hline $3 / 4 \mathrm{~N}^{1 / 4} \mathrm{C}$ & $0,66 \pm 0,1$ & $1,80 \pm 0,2$ & $0,70 \pm 0,1$ & $1,07 \pm 0,2$ & $2,02 \pm 0,2 b$ & $6,83 \pm 0,6$ \\
\hline Média G2 & $0,71 \pm 0,1$ & $1,79 \pm 0,2$ & $0,67 \pm 0,1$ & $1,34 \pm 0,2$ & $2,31 \pm 0,2$ & $7,51 \pm 0,4$ \\
\hline Heterose G2, \% & 2,16 & 20,54 & 11,67 & 9,39 & $28,06 *$ & 15,54 \\
\hline $5 / 8 \mathrm{C} \quad 3 / 8 \mathrm{~N}$ & $0,64 \pm 0,1$ & $1,11 \pm 0,2$ & $0,55 \pm 0,1$ & $1,20 \pm 0,2$ & $2,04 \pm 0,2$ & $6,24 \pm 0,4$ \\
\hline $5 / 8 \mathrm{~N} \quad 3 / 8 \mathrm{C}$ & $0,66 \pm 0,1$ & $1,30 \pm 0,1$ & $0,42 \pm 0,1$ & $1,04 \pm 0,1$ & $1,81 \pm 0,2$ & $5,86 \pm 0,4$ \\
\hline Média G3 & $0,65 \pm 0,1$ & $1,20 \pm 0,1$ & $0,48 \pm 0,1$ & $1,12 \pm 0,1$ & $1,92 \pm 0,1$ & $6,05 \pm 0,3$ \\
\hline Heterose G3, \% & $-6,47$ & $-18,86$ & $-19,17$ & $-8,57$ & 6,94 & $-6,92$ \\
\hline $11 / 16 \mathrm{C} 5 / 16 \mathrm{~N}$ & $0,67 \pm 0,1$ & $1,22 \pm 0,2$ & $0,41 \pm 0,1$ & $1,21 \pm 0,2$ & $1,96 \pm 0,3$ & $6,08 \pm 0,5$ \\
\hline $11 / 16$ N 5/16 C & $0,69 \pm 0,1$ & $1,33 \pm 0,2$ & $0,53 \pm 0,1$ & $1,83 \pm 0,2$ & $1,97 \pm 0,3$ & $7,08 \pm 0,6$ \\
\hline Média G4 & $0,68 \pm 0,1$ & $1,27 \pm 0,1$ & $0,47 \pm 0,1$ & $1,52 \pm 0,2$ & $1,97 \pm 0,2$ & $6,58 \pm 0,4$ \\
\hline Heterose G4, \% & $-2,16$ & $-14,14$ & $-21,67 *$ & 24,08 & 9,17 & 1,23 \\
\hline Heterose retida, \% & $-2,16$ & $-4,15$ & $-9,72$ & 8,30 & 14,72 & 3,28 \\
\hline Diferença cruzados e C, \% & $-2,86$ & $-18,67$ & $-29,65$ & $-5,91$ & 5,36 & $-7,02$ \\
\hline Diferença cruzados e N, \% & $-1,45$ & 16,67 & 25,97 & 27,56 & 25,91 & 16,15 \\
\hline
\end{tabular}

$* \mathrm{P}<0,05$.

Médias na coluna seguidas por letras diferentes na comparação entre $\mathrm{C}$ e $\mathrm{N}$ ou entre os genótipos dentro da mesma geração de cruzamento são diferentes ( $\mathrm{P}<0,10)$ pelo teste t.

intestinal (28,06\%). Na terceira geração, a heterose foi negativa para a maioria das gorduras depositadas nos diferentes locais, mas não foi significativa. Novilhos da quarta geração apresentaram 21,67\% menos gordura de toalete que os animais puros. Quando a quantidade de gorduras foi ajustada para $100 \mathrm{~kg}$ de peso de abate (Tabela 3), apenas a heterose da segunda geração para a gordura inguinal foi significativa (3,15\%). Heteroses negativas nestas características são desejáveis, uma vez que o aumento deste tipo de gordura prejudica o rendimento de carcaça (Peron et al., 1993) e aumenta a exigência de mantença do animal. Segundo Gesualdi Jr. et al. (2001), a gordura depositada internamente tem maior atividade metabólica que o tecido adiposo periférico. De acordo com Leme et al. (2000), as 
Tabela 3 - Pesos, em relação a 100 kg de peso de abate, das gorduras inguinal, renal, de toalete, do rúmen, do intestino e total de novilhos resultantes de cruzamentos Charolês $\times$ Nelore

\begin{tabular}{|c|c|c|c|c|c|c|}
\hline \multirow[t]{2}{*}{ Grupo genético } & \multicolumn{5}{|c|}{ Gordura (\%) } & \multirow[b]{2}{*}{ Total } \\
\hline & Inguinal & Renal & Toalete & Ruminal & Intestinal & \\
\hline Charolês (C) & $0,64 \pm 0,11$ & $1,61 \pm 0,32$ & $0,70 \pm 0,14$ & $1,31 \pm 0,3$ & $1,81 \pm 0,3$ & $6,67 \pm 0,8$ \\
\hline Nelore (N) & $0,63 \pm 0,09$ & $1,12 \pm 0,27$ & $0,39 \pm 0,13$ & $0,94 \pm 0,2$ & $1,50 \pm 0,2$ & $5,27 \pm 0,7$ \\
\hline Média puros & $0,64 \pm 0,07$ & $1,37 \pm 0,20$ & $0,55 \pm 0,09$ & $1,13 \pm 0,2$ & $1,66 \pm 0,2$ & $5,97 \pm 0,5$ \\
\hline $3 / 4 \mathrm{C} 1 / 4 \mathrm{~N}$ & $0,72 \pm 0,09$ & $1,68 \pm 0,28$ & $0,60 \pm 0,13$ & $1,49 \pm 0,2$ & $2,43 \pm 0,2 \mathrm{a}$ & $7,68 \pm 0,7 a$ \\
\hline $3 / 4 \mathrm{~N}^{1 / 4} \mathrm{C}$ & $0,59 \pm 0,08$ & $1,60 \pm 0,23$ & $0,62 \pm 0,10$ & $0,96 \pm 0,2$ & $1,80 \pm 0,2 b$ & $6,06 \pm 0,6 b$ \\
\hline Média G2 & $0,66 \pm 0,06$ & $1,64 \pm 0,18$ & $0,61 \pm 0,08$ & $1,23 \pm 0,2$ & $2,12 \pm 0,2$ & $6,87 \pm 0,5$ \\
\hline Heterose G2, \% & $3,15 * *$ & 20,15 & 11,93 & 8,89 & 27,79 & 15,08 \\
\hline 5/8C 3/8N & $0,57 \pm 0,06$ & $0,99 \pm 0,16$ & $0,49 \pm 0,08$ & $1,06 \pm 0,1$ & $1,80 \pm 0,2$ & $5,54 \pm 0,4$ \\
\hline $5 / 8 \mathrm{~N} 3 / 8 \mathrm{C}$ & $0,58 \pm 0,05$ & $1,13 \pm 0,14$ & $0,36 \pm 0,07$ & $0,90 \pm 0,1$ & $1,57 \pm 0,2$ & $5,10 \pm 0,4$ \\
\hline Média G3 & $0,58 \pm 0,04$ & $1,06 \pm 0,10$ & $0,43 \pm 0,05$ & $0,98 \pm 0,1$ & $1,69 \pm 0,1$ & $5,32 \pm 0,3$ \\
\hline Heterose G3, \% & $-9,45$ & $-25,61$ & $-22,02$ & $-12,89$ & 1,81 & $-10,89$ \\
\hline $11 / 16$ C 5/16 N & $0,57 \pm 0,06$ & $1,05 \pm 0,17$ & $0,35 \pm 0,07$ & $1,05 \pm 0,2$ & $1,70 \pm 0,3$ & $5,24 \pm 0,5$ \\
\hline $11 / 16$ N 5/16 C & $0,64 \pm 0,07$ & $1,23 \pm 0,19$ & $0,49 \pm 0,08$ & $1,70 \pm 0,2$ & $1,82 \pm 0,3$ & $6,55 \pm 0,6$ \\
\hline Média G4 & $0,61 \pm 0,05$ & $1,14 \pm 0,13$ & $0,42 \pm 0,06$ & $1,38 \pm 0,2$ & $1,76 \pm 0,2$ & $5,90 \pm 0,4$ \\
\hline Heterose G4, \% & $-4,72$ & $-20,00$ & $-22,94^{*}$ & 22,22 & 6,34 & $-1,26$ \\
\hline Heterose retida, \% & $-3,67$ & $-6,23$ & $-11,01$ & 6,07 & 11,98 & 0,98 \\
\hline Diferença cruzados e C, \% & $-4,43$ & $-20,50$ & $-30,71$ & $-8,91$ & 2,39 & $-9,62$ \\
\hline Diferença cruzados e N, \% & $-2,91$ & 14,29 & 24,36 & 26,95 & 23,56 & 14,39 \\
\hline
\end{tabular}

$* \mathrm{P}<0,05$.

Médias na coluna seguidas por letras diferentes na comparação entre $\mathrm{C}$ e N, ou entre os genótipos dentro da mesma geração de cruzamento, são diferentes (P<0,10) pelo teste t.

gorduras renal, pélvica e inguinal, expressas em peso absoluto ou relativo, são o melhor indicador da deposição de gordura corporal e a espessura de gordura da carcaça é muitas vezes reduzida com a retirada do couro. Além disso, o excesso de gordura é retirado do corpo do animal antes das pesagens das carcaças e, portanto, não participa da remuneração ao produtor.

Entre os animais puros, os novilhos Charolês apresentaram maior peso absoluto da gordura de toalete em relação aos Nelore (Tabela 1). Trabalhando com os mesmos animais utilizados neste estudo, Menezes et al. (2005a) observaram maior espessura de gordura subcutânea (4,8 e 3,6 mm) nos animais puros. A quantidade de gordura depositada nos diferentes locais, nas diferentes formas de expressão, foi numericamente superior nos novilhos Charolês. Este resultado não está de acordo com a maioria das pesquisas com esses dois genótipos (Restle et al., 1995; Restle et al., 2002), porém é explicado pela alta velocidade de ganho de peso e maior consumo de energia digestível dos animais utilizados neste experimento (Menezes \& Restle, 2005). Quando o peso da gordura de toalete foi expresso em $100 \mathrm{~kg}$ de PCV (Tabela 3), a diferença entre os animais puros deixou de existir.

A maior velocidade de deposição de gordura subcutânea não afetou a deposição de gordura intestinal dos animais, uma vez que não houve diferença entre eles. Esta constatação está de acordo com a de Almeida et al. (2001), que observaram que a deposição de gordura nos intestinos ocorre em taxa muito inferior à do corpo.
Na segunda geração de cruzamento, a gordura depositada nos intestinos foi maior nos animais $3 / 4 \mathrm{C} 1 / 4 \mathrm{~N}$ que nos 3/4 N 1/4C nas três formas de expressão, bem como a gordura total relativa ao peso de abate. Por outro lado, na quarta geração, os 11/16N 5/16C apresentaram maior quantidade absoluta de gordura ruminal. Luchiari Filho et al. (1989) não observaram efeito da inclusão do sangue Canchim (5/8C 3/8N) no cruzamento no peso absoluto da gordura renal, pélvica e inguinal. No entanto, quando os resultados foram em porcentagem, observou-se valor significativamente menor para os mestiços Canchim em relação aos Nelore. Kuss et al. (2007), estudando a terminação de vacas de descarte da segunda e terceira geração do cruzamento Charolês $\times$ Nelore, não observaram interferência do grupo genético, da predominância racial, ou da geração de cruzamento sobre a quantidade de gordura interna, de toalete e total no corpo do animal.

A deposição de gordura no rúmen foi a única que afetou o rendimento de carcaça; a correlação $(P<0,001)$ foi de $-0,26$ e $-0,33$ para os rendimentos de carcaça quente e fria, respectivamente.

Os animais cruzados foram superiores aos puros apenas no peso absoluto das patas na segunda geração do cruzamento, resultando heterose de 11,64\% (Tabela 4). Nos novilhos Charolês, cabeça, patas e vassoura da cauda foram mais pesadas que nos Nelore, mas esta superioridade não refletiu no somatório dos constituintes externos. A superioridade de raças de grande porte sobre raças de menor porte 
no peso desses componentes foi reportada por Jones et al. (1985), que também afirmaram que o peso do couro é maior quando raças de grande porte participam do cruzamento. Neste estudo, não foi observada esta variação em nenhuma das gerações para o peso absoluto do couro. Ferrel \& Jenkis (1998) observaram que o peso absoluto do couro foi semelhante entre raças européias e zebuínas.

A heterose foi negativa e significativa na terceira geração do cruzamento para os pesos de cabeça, patas, couro e conjunto dos órgãos externos relativos ao PCV, resultando em heterose de -15,54; -11,08; -9,44 e-11,10\%, respectivamente (Tabela 5). Na quarta geração do cruzamento, os pesos relativos destes constituintes nos animais mestiços também foram menores que nos puros, porém a heterose foi significativa apenas para o peso relativo da cabeça. Superioridade no peso relativo da cabeça de animais mestiços ( $1 \frac{1}{2}$ Caracu $1 / 2$ Nelore) sobre animais Nelore foi citada por Fernandes et al. (2005). Por outro lado, neste

Tabela 4 - Pesos absolutos de cabeça, patas, vassoura da cauda, couro e do conjunto dos órgãos externos de novilhos resultantes de cruzamentos Charolês $\times$ Nelore

\begin{tabular}{|c|c|c|c|c|c|}
\hline Grupo genético & Cabeça, kg & Patas, kg & Vassoura da cauda, kg & Couro, kg & Órgãos externos, kg \\
\hline Charolês (C) & $15,21 \pm 0,9 a$ & $7,97 \pm 0,4 a$ & $0,37 \pm 0,07 c$ & $32,50 \pm 5,1$ & $56,06 \pm 5,5$ \\
\hline Nelore (N) & $11,67 \pm 0,8 b$ & $5,86 \pm 0,3 b$ & $0,20 \pm 0,06 \mathrm{~d}$ & $32,89 \pm 4,4$ & $50,62 \pm 4,8$ \\
\hline Média puros & $13,44 \pm 0,6$ & $6,91 \pm 0,3$ & $0,29 \pm 0,04$ & $32,70 \pm 3,2$ & $53,34 \pm 3,5$ \\
\hline $3 / 4 \mathrm{C} 1 / 4 \mathrm{~N}$ & $14,41 \pm 0,8$ & $8,01 \pm 0,3$ & $0,33 \pm 0,06$ & $40,92 \pm 4,4$ & $63,67 \pm 4,8$ \\
\hline $3 / 4 \mathrm{~N} 1 / 4 \mathrm{C}$ & $13,72 \pm 0,7$ & $7,43 \pm 0,3$ & $0,32 \pm 0,05$ & $32,79 \pm 3,6$ & $54,26 \pm 3,9$ \\
\hline Média G2 & $14,07 \pm 0,6$ & $7,72 \pm 0,2$ & $0,32 \pm 0,04$ & $36,86 \pm 2,8$ & $58,97 \pm 3,1$ \\
\hline Heterose G2, \% & 4,65 & $11,64 * *$ & 14,04 & 12,72 & 10,55 \\
\hline $5 / 8 \mathrm{C} 3 / 8 \mathrm{~N}$ & $12,87 \pm 0,6$ & $7,10 \pm 0,4$ & $0,33 \pm 0,04$ & $33,48 \pm 1,8$ & $53,78 \pm 2,1$ \\
\hline $5 / 8 N \quad 3 / 8 \mathrm{C}$ & $13,60 \pm 0,5$ & $7,37 \pm 0,3$ & $0,34 \pm 0,03$ & $36,06 \pm 1,5$ & $57,37 \pm 1,9$ \\
\hline Média G3 & $13,24 \pm 0,4$ & $7,23 \pm 0,2$ & $0,34 \pm 0,03$ & $34,77 \pm 1,1$ & $55,57 \pm 1,4$ \\
\hline Heterose G3, \% & $-1,53$ & 4,63 & 17,54 & 6,35 & 4,19 \\
\hline $11 / 16$ C $5 / 16 \mathrm{~N}$ & $13,46 \pm 0,7$ & $6,99 \pm 0,7$ & $0,29 \pm 0,05$ & $36,58 \pm 2,1$ & $57,32 \pm 2,7$ \\
\hline $11 / 16$ N 5/16 C & $13,99 \pm 0,8$ & $7,33 \pm 0,6$ & $0,32 \pm 0,05$ & $36,53 \pm 2,3$ & $58,16 \pm 3,0$ \\
\hline Média G4 & $13,73 \pm 0,5$ & $7,16 \pm 0,4$ & $0,31 \pm 0,04$ & $36,56 \pm 1,6$ & $57,74 \pm 2,1$ \\
\hline Heterose G4, \% & 2,12 & 3,54 & 7,02 & 11,81 & 8,25 \\
\hline Heterose retida, \% & 1,75 & 6,60 & 12,87 & 10,29 & 7,66 \\
\hline Diferença cruzados e C, \% & $-10,09 * * *$ & $-7,51 * *$ & $-13,06 * *$ & 10,95 & 2,44 \\
\hline Diferença cruzados e N, \% & $17,18 * *$ & $25,80 * *$ & $60,83 * *$ & 9,64 & $13,45 *$ \\
\hline
\end{tabular}

$* * * \mathrm{P}<0,01 ; * * \mathrm{P}<0,05 ; * \mathrm{P}<0,10$.

Médias na coluna seguidas por letras diferentes na comparação entre $\mathrm{C}$ e $\mathrm{N}$, ou entre os genótipos dentro da mesma geração de cruzamento, são diferentes ( $\mathrm{P}<0,05$ (a,b); $\mathrm{P}<0,10\left({ }^{(\mathrm{c}, \mathrm{d}}\right)$ ) pelo teste $\mathrm{t}$.

Tabela 5 - Pesos, em relação a 100 kg de peso de corpo vazio, de cabeça, patas, cauda, couro e do conjunto dos órgãos externos de novilhos resultantes de cruzamentos Charolês $\times$ Nelore

\begin{tabular}{|c|c|c|c|c|c|}
\hline Grupo genético & Cabeça, \% & Patas, \% & Vassoura da cauda, \% & Couro, \% & Órgãos externos, \% \\
\hline Charolês (C) & $4,16 \pm 0,3$ & $2,18 \pm 0,1 \mathrm{a}$ & $0,11 \pm 0,02$ & $8,90 \pm 1,2$ & $15,35 \pm 1,1$ \\
\hline Nelore (N) & $3,69 \pm 0,2$ & $1,88 \pm 0,1 b$ & $0,06 \pm 0,02$ & $10,37 \pm 1,0$ & $15,99 \pm 1,0$ \\
\hline Média puros & $3,93 \pm 0,2$ & $2,03 \pm 0,1$ & $0,09 \pm 0,01$ & $9,63 \pm 0,8$ & $15,67 \pm 0,6$ \\
\hline $3 / 4 \mathrm{C}^{1 / 4 \mathrm{~N}}$ & $3,68 \pm 0,2$ & $2,04 \pm 0,1$ & $0,08 \pm 0,02$ & $10,40 \pm 1,0$ & $16,19 \pm 1,0 \mathrm{~d}$ \\
\hline $3 / 4 \mathrm{~N}^{1 / 4} \mathrm{C}$ & $3,57 \pm 0,2$ & $1,93 \pm 0,1$ & $0,08 \pm 0,01$ & $8,25 \pm 0,9$ & $13,82 \pm 0,8 c$ \\
\hline Média G2 & $3,63 \pm 0,1$ & $1,99 \pm 0,1$ & $0,08 \pm 0,01$ & $9,32 \pm 0,7$ & $15,01 \pm 0,6$ \\
\hline Heterose G2, \% & $-7,64$ & $-2,22$ & $-5,88$ & $-3,22$ & $-4,24$ \\
\hline $5 / 8 \mathrm{C} 3 / 8 \mathrm{~N}$ & $3,26 \pm 0,1$ & $1,80 \pm 0,1$ & $0,09 \pm 0,01$ & $8,54 \pm 0,4$ & $13,69 \pm 0,5$ \\
\hline $5 / 8 \mathrm{~N} 3 / 8 \mathrm{C}$ & $3,37 \pm 0,1$ & $1,81 \pm 0,1$ & $0,08 \pm 0,01$ & $8,91 \pm 0,4$ & $14,17 \pm 0,4$ \\
\hline Média G3 & $3,32 \pm 0,1$ & $1,81 \pm 0,1$ & $0,08 \pm 0,01$ & $8,73 \pm 0,3$ & $13,93 \pm 0,3$ \\
\hline Heterose G3, \% & $-15,54 * * *$ & $-11,08 * *$ & 00,00 & $-9,44 *$ & $-11,10 * * *$ \\
\hline $11 / 16$ C $5 / 16 \mathrm{~N}$ & $3,20 \pm 0,2 b$ & $1,67 \pm 0,2$ & $0,07 \pm 0,01$ & $8,75 \pm 0,5$ & $13,69 \pm 0,6$ \\
\hline $11 / 16$ N 5/16 C & $3,62 \pm 0,2 \mathrm{a}$ & $1,87 \pm 0,1$ & $0,08 \pm 0,02$ & $9,39 \pm 0,5$ & $14,97 \pm 0,6$ \\
\hline Média G4 & $3,41 \pm 0,1$ & $1,77 \pm 0,1$ & $0,08 \pm 0,01$ & $9,07 \pm 0,4$ & $14,33 \pm 0,4$ \\
\hline Heterose G4, \% & $-13,12 * *$ & $-12,81$ & $-11,76$ & $-5,86$ & $-8,55$ \\
\hline Heterose retida, \% & $-12,10 * * *$ & $-8,70 *$ & $-5,88$ & $-6,18$ & $-7,97 *$ \\
\hline Diferença cruzados e C, & $-17,07$ & $-14,98$ & $-27,27 * *$ & 1,57 & $-6,05$ \\
\hline Diferença cruzados e N, \% & $-6,50$ & $-1,42$ & 33,33 & $-12,83$ & $-9,81 *$ \\
\hline
\end{tabular}

$* * * \mathrm{P}<0,01 ; * * \mathrm{P}<0,05 ; * \mathrm{P}<0,10$.

Médias na coluna seguidas por letras diferentes na comparação entre $\mathrm{C}$ e N, ou entre os genótipos dentro da mesma geração de cruzamento, são diferentes ( $<<0,10)$ pelo teste t. 
estudo os animais Nelore foram 9,81\% superiores aos mestiços no somatório dos pesos relativos dos órgãos externos. Esta diferença não afetou o rendimento de carcaça destes animais, conforme observado por Menezes et al. (2005b) nesses mesmos animais.

Entre os animais puros, a única diferença que permaneceu em relação aos pesos absolutos foi o peso relativo das patas, que foi $13,76 \%$ maior $(\mathrm{P}<0,10)$ nos animais Charolês (Tabela 5 e 6).

Na quarta geração do cruzamento, os 11/16N 5/16C apresentaram maior peso relativo da cabeça em comparação aos 11/16C 5/16N. O peso relativo da cabeça apresentou correlação de -0,44 e -0,48 ( $\mathrm{P}<0,01)$ com os rendimentos de carcaça quente e fria, respectivamente. A diferença no peso relativo da cabeça entre os animais da quarta geração do cruzamento não prejudicou o rendimento de carcaça destes animais, conforme verificado por Menezes et al. (2005b), nesses mesmos animais.

Nos animais Nelore, o peso relativo do couro foi $14,46 \%$ maior $(\mathrm{P}>0,10)$ que nos Charolês (Tabela 6). Peron et al. (1993) relacionaram o maior peso relativo do couro de animais Nelore a sua maior área corporal, pois apresentam giba e barbela mais desenvolvidas. Galvão et al. (1991) também observaram maior peso relativo do couro em animais Nelore em relação aos seus mestiços com Limousin e Marchigiana. Assim como nestes estudos, a diferença no peso relativo do couro não foi suficiente para prejudicar o rendimento de carcaça. Não houve relação entre o peso relativo do couro e o rendimento de carcaça fria $(R=-0,14$; $\mathrm{P}>0,05)$.

Tabela 6 - Pesos, em relação a 100 kg de peso de abate da cabeça, patas, cauda, couro e do conjunto dos órgãos externos de novilhos, de acordo com o grupo genético

\begin{tabular}{lccccc}
\hline Grupo genético & Cabeça, $\%$ & Patas, $\%$ & Vassoura da cauda, $\%$ & Couro, \% & Órgãos externos, \% \\
\hline Charolês (C) & $3,82 \pm 0,3$ & $2,01 \pm 0,1$ & $0,10 \pm 0,02$ & $8,16 \pm 1,1$ & $14,09 \pm 1,2$ \\
Nelore (N) & $3,37 \pm 0,2$ & $1,7 \pm 0,1$ & $0,06 \pm 0,02$ & $9,41 \pm 1,0$ & $14,55 \pm 1,1$ \\
Média puros & $3,60 \pm 0,2$ & $1,86 \pm 0,1$ & $0,08 \pm 0,01$ & $8,79 \pm 0,7$ & $14,32 \pm 0,8$ \\
3/4C 1/4N & $3,45 \pm 0,2$ & $1,90 \pm 0,1$ & $0,08 \pm 0,02$ & $9,73 \pm 1,0$ & $15,16 \pm 1,1$ \\
3/4N 1/4C & $3,16 \pm 0,2$ & $1,71 \pm 0,1$ & $0,07 \pm 0,01$ & $7,37 \pm 0,8$ & $12,31 \pm 0,9$ \\
Média G2 & $3,31 \pm 0,2$ & $1,81 \pm 0,1$ & $0,08 \pm 0,01$ & $8,55 \pm 0,6$ & $13,74 \pm 0,7$ \\
Heterose G2, \% & $-8,07$ & $-2,70$ & $-6,25$ & $-2,68$ & $-4,09$ \\
5/8C 3/8N & $2,88 \pm 0,2$ & $1,59 \pm 0,1$ & $0,08 \pm 0,01$ & $7,49 \pm 0,4$ & $12,04 \pm 0,5$ \\
5/8N 3/8C & $2,93 \pm 0,1$ & $1,58 \pm 0,1$ & $0,07 \pm 0,01$ & $7,75 \pm 0,3$ & $12,33 \pm 0,4$ \\
Média G3 & $2,91 \pm 0,1$ & $1,59 \pm 0,1$ & $0,08 \pm 0,01$ & $7,62 \pm 0,2$ & $12,19 \pm 0,3$ \\
Heterose G3, \% & $-19,19$ & $-14,56 * *$ & $-6,25$ & $-13,26 * *$ & $-14,91 * *$ \\
11/16 C 5/16 N & $2,75 \pm 0,2 \mathrm{~b}$ & $1,42 \pm 0,1$ & $0,06 \pm 0,01$ & $7,52 \pm 0,5$ & $11,75 \pm 0,6$ \\
11/16 N 5/16 C & $3,35 \pm 0,2 \mathrm{a}$ & $1,73 \pm 0,1$ & $0,08 \pm 0,01$ & $8,65 \pm 0,5$ & $13,80 \pm 0,7$ \\
Média G4 & $3,05 \pm 0,1$ & $1,58 \pm 0,1$ & $0,07 \pm 0,01$ & $8,09 \pm 0,4$ & $12,78 \pm 0,5$ \\
Heterose G4, \% & $-15,16 * *$ & $-15,09$ & $-12,50$ & $-7,97$ & $-10,79$ \\
Heterose retida, \% & $-14,14 *$ & $-10,78 * * *$ & $-8,33$ & $-7,97$ & $-9,93 * * *$ \\
Diferença cruzados e C, \% & $-19,20$ & $-17,66$ & $-26,67 * *$ & $-0,92$ & $-8,46$ \\
Diferença cruzados e N, \% & $-8,41$ & $-2,65$ & 22,22 & $-14,08 *$ & $-11,35^{*}$ \\
\hline
\end{tabular}

$* * * \mathrm{P}<0,01 ; * * \mathrm{P}<0,05 ; * \mathrm{P}<0,10$.

Médias na coluna seguidas por letras diferentes na comparação entre $\mathrm{C}$ e N, ou entre os genótipos dentro da mesma geração de cruzamento, são diferentes ( $<<0,10$ ) pelo teste t.

\section{Conclusões}

Novilhos da segunda geração do cruzamento entre as raças Charolês e Nelore apresentam maior heterose para a quantidade absoluta de gorduras renal, intestinal e total, enquanto novilhos da quarta geração de cruzamento mostram maior heterose para gordura ruminal. No entanto, quando os valores são expressos em relação aos pesos de corpo vazio e de abate, a porcentagem de heterose decresce em ambas as gerações. Novilhos das três gerações de cruzamento apresentam heterose negativa quando os valores dos componentes externos são expressos em relação aos pesos de corpo vazio e de abate, portanto, a heterose é mais expressiva na terceira geração. A heterose retida é expressiva e positiva para os valores absolutos da gordura intestinal e total; e negativa para os componentes externos quando os valores são expressos em relação aos pesos de corpo vazio e de abate. 


\section{Literatura Citada}

ALMEIDA, M.I.V.; FONTES, C.A.A.; ALMEIDA, F.Q. et al. Avaliação do crescimento compensatório de tecidos e órgãos de novilhos mestiços Holandês-Gir durante o ganho compensatório. 2. Tecidos e órgãos. Revista Brasileira de Zootecnia, v.30, n.2, p.535-545, 2001.

DI MARCO, O.N. Crecimiento de vacunos para carne. 1.ed. Mar del Plata, 1998, 246p.

FERNANDES, H.J.; PAULINO, M.F.; GALVÃO, R.M. et al. Crescimento de componentes corporais de três grupos genéticos nas fases de recria e terminação. Revista Brasileira de Zootecnia, v.34, n.1, p.288-296, 2005.

FERREL, C.L.; JENKIS, T.G. Body composition and energy utilization by steers of diverse genotypes fed a high-concentrate diet during the finishing period: Angus, Boran, Brahman, Hereford and Tuli sires. Journal of Animal Science, v.76, n.2, p.647-657, 1998.

GALVÃO, J.G.; FONTES, C.A.A.; PIRES, C.C. et al. Características e composição da carcaça de bovinos não castrados, abatidos em três estágios de maturidade (estudo II) de três grupos raciais. Revista da Sociedade Brasileira de Zootecnia, v.20, n.5, p.502-512, 1991.

GESUALDI JR., A.; VELOSO, C.M.; PAULINO, M.F. et al. Níveis de concentrado na dieta de bovinos F1 Limousin x Nelore: peso dos órgãos internos e trato digestivo. Revista Brasileira de Zootecnia, v.30, n.6, p.1866-1871, 2001.

GREGORY, K.E.; CROUSE, J.D.; KOCH, D.B. et al. Heterosis and breed maternal and transmitted effects in beef cattle. IV. Carcass traits of steers. Journal of Animal Science, v.47, n.5, p.1063-1079, 1978.

HEDRICK, H.B.; KRAUSE, G.F.; LASLEY, J.F. et al. Quantitative and qualitative carcass characteristics of straightbred and reciprocally crossed Angus, Charolais and Hereford steers. Journal of Animal Science, v.41, n.6, p.1581-1591, 1975.

JONES, S.M.D.; ROMPALA, R.E.; JEREMIAH, L.E. Growth and composition of the empty body in steers of different maturity types fed concentrate or forage diets. Journal of Animal Science, v.60, n.2, p.427-433, 1985.

KOGER, M. Effective crossbreeding systems utilizing zebu cattle. Journal of Animal Science, v.50, n.6, p.1213-1220, 1980.

KUSS, F.; RESTLE, J.; BRONDANI, I.L. et al. Componentes externos do corpo e gordura de descarte em vacas mestiças Charolês x Nelore abatidas com diferentes pesos. Revista Brasileira de Zootecnia, v.36, n.4, p.865-873, 2007.

LEME, P.R.; BOIN, C.; MARGARIDO, R.C.C. et al. Desempenho em confinamento e características de carcaça de bovinos machos de diferentes cruzamentos abatidos em três faixas de peso. Revista Brasileira de Zootecnia, v.29, n.6, p.2347-2353, 2000 (supl. 2).

LONG, C.R.; GREGORY, K.E. Heterosis and management effects in carcass characters of Angus, Hereford and reciprocal cross cattle. Journal of Animal Science, v.41, n.6, p.1572-1579, 1975.

LUCHIARI FILHO, A.; LEME, P.R.; RAZOOK, A.G. et al. Características de carcaça e rendimento de porção comestível de machos Nelore comparados a cruzados (F1) obtidos do acasalamento de touros das raças Canchim, Santa Gertrudis, Caracu, Holandês e Suíço com fêmeas Nelore. II. Animais castrados terminados a pasto. Boletim da Indústria Animal, v.46, n.1, p.27-35, 1989.

MARSHALL, T.T.; HARGROVE, D.D.; OLSON, T.A. Heterosis and additive breed effects on feedlot and carcass traits from crossing Angus and Brown Swiss. Journal of Animal Science, v.64, n.5, p.1332-1339, 1987.
MENEZES, L.F.G.; RESTLE, J.; BRONDANI, I.L. et al. Características da carcaça de novilhos de gerações avançadas do cruzamento alternado entre as raças charolês e nelore, terminados em confinamento. Revista Brasileira de Zootecnia, v.34, n.3, p.934-945, 2005b.

MENEZES, L.F.G.; RESTLE, J.; VAZ, F.N. et al. Composição física da carcaça e qualidade da carne de novilhos de gerações avançadas do cruzamento alternado entre as raças Charolês e Nelore, terminados em confinamento. Revista Brasileira de Zootecnia, v.34, n.3, p.946-956, 2005a.

MENEZES, L.F.G.; RESTLE, J. Desempenho de novilhos de gerações avançadas do cruzamento alternado entre as Raças Charolês e Nelore, terminados em confinamento. Revista Brasileira de Zootecnia, v.34, n.6, p.1927-1937, 2005 (supl.).

NATIONAL RESEARCH COUNCIL - NRC. Nutrient requirement of beef cattle. 7.ed. Washington, D.C.: National Academy Press, 1996. 242p.

PACHECO, P.S.; RESTLE, J.; SILVA, J.H.S. et al. Características das partes do corpo não-integrantes da carcaça de novilhos jovens e superjovens de diferentes grupos genéticos. Revista Brasileira de Zootecnia, v.34, n.5, p.1678-1690, 2005.

PERON, A.J.; FONTES, C.A.A.; LANA, R.P. et al. Tamanho de órgãos internos e distribuição da gordura corporal em novilhos de cinco grupos genéticos, submetidos a alimentação restrita e ad libitum. Revista Brasileira de Zootecnia, v.22, n.5, p.813819, 1993.

RESTLE, J.; FELTEN, H.G.; VAZ, F.N. Efeito da raça e heterose para características quantitativas da carcaça de novilhos de 24 meses terminados em confinamento. In: REUNIÓN LATINOAMERICANA DE PRODUCCIÓN ANIMAL, 14., 1995, Mar del Plata. Memorias... Balcare: ALPA, 1995. n.3-4, p.857-859.

RESTLE, J.; MENEZES, L.F.G.; ARBOITTE, M.Z. et al. Características das partes não-integrante da carcaça de novilhos 5/6 Nelore 3/8 Charolês abatidos em três estádios de desenvolvimento. Revista Brasileira de Zootecnia, v.34, n.4, p.1339-1348, 2005.

RESTLE, J.; PASCOAL, L.L.; FATURI, C. et al. Efeito do grupo genético e da heterose nas características quantitativas da carcaça de vacas de descarte terminadas em confinamento. Revista Brasileira de Zootecnia, v.31, n.1, p.350-362, 2002 (supl.).

STATISTICAL ANALYSIS SYSTEM - SAS. SAS'S user's guide. SAS for Windows. Cary: SAS Institute, 1997. 46p.

SLANGER, W.D.; MARCHELLO, M.J.; DANIELSON, R.B., et al. Muscle tenderness, other carcass traits and the effect of crossbreeding on theses traits in beef cattle. Journal of Animal Science, v.61, n.6, p.1402-1410, 1985.

SOLIS, J.C.; BYERS, F.M.; SCHELLING, G.T. et al. Maintenance requirements and energetic efficiency of cows of different breed types. Journal of Animal Science, v.66, n.3, p.764-774, 1988 (suppl. 1).

THOMPSON, W.R.; MEISKE, J.C.; GOODRICH, R.D. et al. Influence of body composition on energy requirement of breed cows during winter. Journal of Animal Science, v.56, n.5, p.1241-1251, 1983.

URICK, J.J.; PAHNISH, O.F.; KNAPP, B.W. et al. Comparison of two- and three-way rotational crossing, beef $\mathrm{x}$ beef and beef $\mathrm{x}$ brown swiss composite breed production: postweaning growth and carcass traits. Journal of Animal Science, v.67, n.10, p.2603-2618, 1989.

VAZ, F.N.; RESTLE, J.; VAZ, R.Z. et al. Efeitos de raça e heterose na composição física da carcaça e na qualidade da carne de novilhos da primeira geração de cruzamento entre Charolês e Nelore. Revista Brasileira de Zootecnia, v.31, n.1, p.376-386, 2002 (supl.). 